\title{
Absence of Airway Secretion Accumulation Predicts Tolerance of Noninvasive Ventilation in Subjects With Amyotrophic Lateral Sclerosis
}

\author{
Nadia Vandenberghe MD, Anne-Evelyne Vallet MD, Thierry Petitjean MD, Pierre Le Cam MD, \\ Stéphane Peysson MD, Claude Guérin MD PhD, Frédéric Dailler MD, Sylvie Jay MD, \\ Vincent Cadiergue MD, Françoise Bouhour MD, Isabelle Court-Fortune MD, \\ Jean-Philippe Camdessanche MD PhD, Jean-Christophe Antoine MD PhD, \\ François Philit MD, Pascal Beuret MD, Sylvie Bin-Dorel MD, \\ Christophe Vial MD, and Emmanuel Broussolle MD PhD
}

\begin{abstract}
OBJECTIVE: To assess factors that predict good tolerance of noninvasive ventilation (NIV), in order to improve survival and quality of life in subjects with amyotrophic lateral sclerosis. METHODS: We conducted a prospective study in subjects with amyotrophic lateral sclerosis and requiring NIV. The primary end point was NIV tolerance at 1 month. Subjects, several of whom failed to complete the study, were classified as "tolerant" or "poorly tolerant," according to the number of hours of NIV use (more or less than $4 \mathrm{~h}$ per night, respectively). RESULTS: Eighty-one subjects, 73 of whom also attended the 1-month follow-up visit, participated over 34 months. NIV tolerance after the first day of utilization predicted tolerance at 1 month $(77.6 \%$ and $75.3 \%$ of subjects, respectively). Multivariate analysis disclosed 3 factors predicting good NIV tolerance: absence of airway secretions accumulation prior to NIV onset (odds ratio 11.5); normal bulbar function at initiation of NIV (odds ratio 8.5); and older age (weakly significant, odds ratio 1.1). CONCLUSION: Our study reveals 3 factors that are predictive of good NIV tolerance, in particular the absence of airway secretion accumulation, which should prompt NIV initiation before its appearance. Key words: prognosis; cohort studies; amyotrophic lateral sclerosis; noninvasive ventilation tolerance; airway secretion accumulation; mechanically assisted cough. [Respir Care 2013;58(9):1424-1432. () 2013 Daedalus Enterprises]
\end{abstract}

\section{Introduction}

Amyotrophic lateral sclerosis (ALS) is a devastating disease, affecting respiratory muscles and causing breath-

Dr Vandenberghe is affiliated with Service d'Electroneuromyographie et Service de Neurologie C, Centre Sclérose Latérale Amyotrophique de Lyon, Hôpital Neurologique Pierre Wertheimer, Hospices Civils de Lyon, Lyon, France. Drs Vallet, Peysson, and Broussolle are affiliated with Service de Neurologie C, Faculté de Médecine Lyon Sud, Hôpital Neurologique Pierre Wertheimer, Hospices Civils de Lyon, Université Lyon 1, and with Centre National de la Recherche Scientifique, Unité Mixte de Recherche 5229, Lyon, France. Drs Petitjean, Le Cam, Guérin, and Philit are affiliated with Service de Réanimation Médicale et d'Assistance Respiratoire, Hôpital de la Croix Rousse, Hospices Civils de Lyon, Lyon, France. Dr Dailler is affiliated with Service de Réanimation Neurologique, Hôpital Neurologique Pierre Wertheimer, Hospices Civils de Lyon, Lyon, France. Drs Jay and Cadiergue are affiliated lessness, morning headaches, unrefreshing sleep, daytime sleepiness, fatigue, impaired concentration, and poor appetite. ${ }^{1}$ Respiratory failure is the most common cause of

\footnotetext{
with Réanimation Polyvalente Adulte, Centre Hospitalier d'Annonay, Annonay, France. Drs Bouhour and Vial are affiliated with Service d'Electroneuromyographie et des Pathologies Musculaires, Hospices Civils de Lyon, Hôpital Neurologique Pierre Wertheimer, Lyon, France. Dr Court-Fortune is affiliated with Service de Pneumologie B, Hôpital Nord, St Etienne, France. Drs Camdessanche and Antoine are affiliated with Service de Neurologie, Centre Sclérose Latérale Amyotrophique, Hôpital Nord, St Etienne, France. Dr Beuret is affiliated with Service de Réanimation, Centre Hospitalier Général de Roanne, Roanne, France. Dr Bin-Dorel is affiliated with Pôle Information Médicale Evaluation Recherche, Unité de Recherche Clinique, Hospices Civils de Lyon, Université de Lyon, Réseau d'Epidémiologie Clinique International Francophone, Équipes d'Accueil Santé Individu Société 4129, Université Lyon 1, Lyon, France.
} 
death. ${ }^{2,3}$ Noninvasive ventilation (NIV) improves survival and quality of life in ALS patients. ${ }^{4-6}$ Tolerance is known to correlate with longer survival and improved quality of life. Previous studies on NIV tolerance in ALS patients have yielded controversial results regarding age (most of the studies concluded that younger patients are more likely to benefit from NIV or did not retain this criterion as specific), ${ }^{7}$ whereas the majority demonstrated less tolerance in patients with bulbar involvement at NIV initiation. ${ }^{4-13}$ The latter population requires careful attention in the clinical management of problems such as excess saliva and in the choice of the NIV interface, choice of ventilator, and ventilator settings.

See the Related Editorial on Page 1555

Identification of factors that predict good NIV tolerance is a major issue. Implementation of medical support is required as soon as respiratory failure becomes substantial, to enable patients to obtain maximum benefit from treatment. ${ }^{4-12,14,15}$ Most clinicians caring for ALS patients face the dilemma of either premature or belated introduction of NIV. The former can result in the failure and subsequent refusal of the treatment because of the discomfort involved. The latter may increase the risk of respiratory failure and admission to intensive care.

In a previous retrospective study we assessed factors predicting survival following NIV. ${ }^{14}$ Both advanced age and airway secretion accumulation predicted poorer prognosis. These results prompted us to conduct a prospective study to determine whether clinical and pulmonary parameters at initiation play a role in NIV tolerance.

\section{Methods}

This was a descriptive study of a cohort of ALS patients followed by 2 French ALS centers: Service d'Electroneuromyographie et Service de Neurologie C, Centre Sclérose Latérale Amyotrophique de Lyon, Hôpital Neurologique Pierre Wertheimer, Lyon, and Service de Neurologie, Centre Sclérose Latérale Amyotrophique, Hôpital Nord, St Etienne, France. This observational work entailed

\footnotetext{
This study was funded by the Association Lyonnaise de Logistique Post Hospitalière, France. The authors have disclosed no conflicts of interest.

Correspondence: Nadia Vandenberghe MD, Service d'Electroneuromyographie et Service de Neurologie C, Centre Sclérose Latérale Amyotrophique de Lyon, Hôpital Neurologique Pierre Wertheimer, 59 Boulevard Pinel, 69677 Lyon-Bron CEDEX, France. E-mail: nadia. vandenberghe@chu-lyon.fr.
}

DOI: $10.4187 /$ respcare. 02103

\section{QUICK LOOK}

\section{Current knowledge}

Noninvasive ventilation (NIV) can improve quality of life in patients with amyotrophic lateral sclerosis (ALS). Improved tolerance of NIV is associated with better quality of life.

\section{What this paper contributes to our knowledge}

Three factors predicted good NIV tolerance in ALS patients: absence of accumulation of airway secretions prior to NIV initiation, normal bulbar function at NIV initiation, and older age. Absence of secretion accumulation was by far the strongest predictor of NIV success.

no additional visits or examinations for the subjects. The study was approved by the institutional ethical committee, and all subjects gave written informed consent.

\section{Subjects}

We included patients with probable or definite ALS, ${ }^{16}$ treated by riluzole and referred to us between 2006 and 2009, and requiring NIV initiation. Subjects benefited from quarterly monitoring, as recommended ${ }^{17,18}$ and most were prescribed NIV by bi-level positive airway pressure in the $\mathrm{S} / \mathrm{T}$ mode. A few subjects were treated with the volumetargeted NIV method, following immediate intolerance to the bi-level positive airway pressure mode after a 4-hour trial. NIV was proposed when at least one clinical respiratory symptom was present (orthopnea of under 3 months onset; dyssomnia due to respiratory sleep disorders, with insomnia or suffocating wake-ups; nightmares; headaches; non-restorative sleep; paradoxical breathing), in association with at least one abnormal pulmonary function value: slow vital capacity $<50 \%$ of predicted; nocturnal $\mathrm{S}_{\mathrm{pO}_{2}}$ of $<90 \%$ for $>5 \%$ of recording time; daytime (10:00 $\mathrm{AM}$ to 6:00 PM); or $\mathrm{P}_{\mathrm{aCO}_{2}}>45 \mathrm{~mm} .{ }^{16,17}$ Duration of NIV use (hours per night and per $24 \mathrm{~h}$ ) was obtained from the NIV machines. Once NIV was scheduled, it commenced within the following month. When the need for NIV was deemed urgent or semi-urgent, treatment commenced within 1-10 days. Exclusion criteria for the study were: associated chronic respiratory insufficiency such as COPD, other rapidly progressing diseases with a survival expectancy of $<1$ month, tracheotomy, and behavioral or psychiatric disorders that might compromise NIV adherence.

The study's primary end point was NIV tolerance at 1 month. Good tolerance was defined as NIV use for $>4$ consecutive hours each night. Poor tolerance was defined as NIV use for $\leq 4$ consecutive hours per night. ${ }^{11}$ Several subjects failed to complete the study and were 
released either before commencing NIV or in the period between NIV initiation and the 1 month visit. These subjects were included in the group with poor NIV tolerance.

\section{Clinical Data}

The following data were collected prospectively: sex, age at ALS onset and at NIV initiation, nutritional status, body mass index, current smoking, smoking history (in pack-years), place of residence, delay between first clinical signs and ALS diagnosis, revised El Escorial criteria classification of ALS, bulbar function at initiation of NIV, ALS Functional Rating Scale-Revised (ALSFRS-R) score, Norris bulbar scale score, and Epworth daytime sleepiness scale score. Subjects were classified as having ALS with bulbar involvement when the ALSFRS-R score component pertaining to speech or swallowing impairment was $\leq 7 / 8$. When the subscore was $8 / 8$, the subject was classified as having non-bulbar ALS or the pure spinal form at NIV initiation. ${ }^{15,19,20}$ We also used the saliva subcomponent of the ALSFRS-R (with a total score of 12) and decided arbitrarily and a priori that a score of $\leq 9 / 12$ corresponded to bulbar form at NIV initiation. Respiratory status was assessed from dyssomnia, paradoxical breathing, and pulmonary function test results. Slow vital capacity was obtained (SpiroAir, Medisoft/Morgan Scientific, Haverhill, Massachusetts) with the subject in the seated position. Vital capacity was not measured in the supine position because it is too difficult in subjects with severe disabilities. $\mathrm{P}_{\mathrm{aCO}}$ was obtained from arterial blood samples during the daytime (10:00 AM to 6:00 PM, ABL825 Radiometer, Brønshøj, Denmark). Nocturnal oximetry was via pulse oximeter with infrared pulse-oximeter and a multisite finger-clip probe (Pulsox 300i, Konica/Minolta, Tokyo, Japan). Pulmonary function and nocturnal oximetry were measured in 2 laboratories at the same time. Most of the time subjects were propped up at $45^{\circ}$ during sleep, and adjusted their sleeping position to minimize dyspnea. We recorded the proportion of time during which $\mathrm{S}_{\mathrm{pO}_{2}}$ was $<90 \%$.

We had the following NIV titration protocol for the subjects. We started with choosing a mask model, following clinical signs and adjusting the interface to minimize discomfort (air leaks, face/nose pain, nasal congestion, aerophagia). The initial NIV pressures were low (inspiratory pressure $8-10 \mathrm{~cm} \mathrm{H}_{2} \mathrm{O}$, expiratory pressure $4 \mathrm{~cm} \mathrm{H}_{2} \mathrm{O}$ ) and the backup breathing frequency was 14 breaths/min. These parameters were readjusted based on adherence, tolerance, $\mathrm{S}_{\mathrm{pO}_{2}}$, and arterial blood gases.

NIV characterization was based on the following variables at onset: the subject's age, ALS duration, time elapsed between indication for and start of NIV, presence of gastrostomy, NIV tolerance after the first day of use, NIV inspiratory and expiratory pressure, backup breathing frequency, type of NIV interface (commercially available or individually customized mask). Airway secretion accumulation in the lower airways was assessed by auscultation in the subglottic area. A physiotherapist specialized in respiratory diseases also evaluated the subjects. This assessment included drainage maneuvers, clinical examination, and thoracic mobilization. A small nasopharyngeal suctioning was performed in case of doubt about the exact location of the secretion accumulation. If the subject was improved by this suctioning, the secretion accumulation was considered above the glottis. If discomfort persisted and other observations in the physiotherapy assessment suggested it, the secretion accumulation was considered subglottic. Mechanically assisted cough (Alpha 200, Salvia Lifetec, Kronberg, Germany, or CoughAssist, Philips Respironics, Murrysville, Pennsylvania) was administered to all subjects with lower airway secretion accumulation, and when peak cough flow was $<270 \mathrm{~L} / \mathrm{min}$. With the Alpha 200 we used the following protocol for mechanically assisted cough. We use a face mask or end piece with oral intake, and with the subject in half-sitting or lying position. A maximum inspiratory pressure of $30-40 \mathrm{~cm} \mathrm{H}_{2} \mathrm{O}$ is repeated for 5-10 cycles, depending on tolerance and secretion-removal efficiency. We used the following protocol with the CoughAssist. We use a face mask, with the subject in a sitting position. The maximum inspiratory pressure range was $30-40 \mathrm{~cm} \mathrm{H}_{2} \mathrm{O}$, and the maximum expiratory pressure range was $35-40 \mathrm{~cm} \mathrm{H}_{2} \mathrm{O}$. The ratio of inspiratory time to expiratory time was $2 / 1$, and we repeated 5-10 cycles, depending on tolerance and secretionremoval efficiency.

Any pooling of saliva was treated either by suction, medical treatment, botulinum toxin, or by a combination of all 3 before NIV initiation. Subjects who were eligible for NIV but who were not included in the protocol (exclusion criteria or refusal to participate), also benefitted from its implementation and the usual monitoring. Subjects were discharged from hospital on average after 2-3 days. When subjects went home, home visits were performed systematically: the day of going home, at 15 days, and at 48 hours before the evaluation at 1 month, by the nurse and home technician who delivered material. In case of a problem, the ALS center was warned within the following 24 hours.

\section{Statistical Analysis}

Variables are expressed as mean $\pm \mathrm{SD}$, minimum and maximum values (when quantitative), or counts and percentages (when qualitative). The sample size was computed to detect an odds ratio of 0.25 (95\% CI $0.07-0.90$ ) on the basis of the primary objective at first order of risk of 5\%, according to the Miettinens method. ${ }^{21}$ We therefore determined that the inclusion of 80 subjects would fulfill this requirement. 


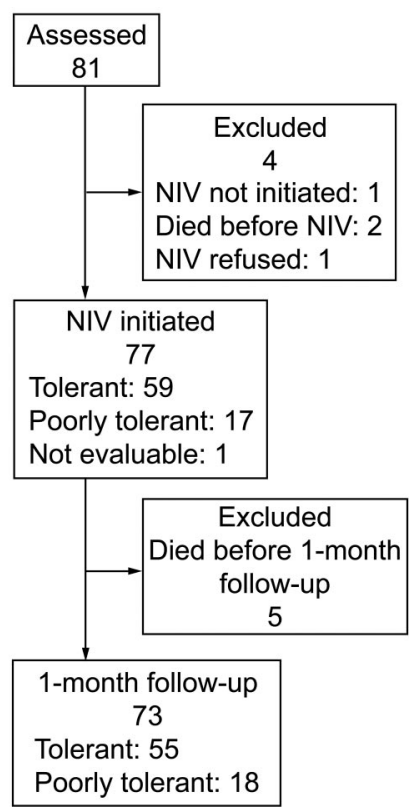

Figure. Flow chart.

Univariate comparisons between tolerant and intolerant NIV subjects were performed using a nonparametric MannWhitney test for quantitative variables, and a chi-square test for categorical variables when conditions permitted (otherwise, we used the Fisher exact test). In the univariate analysis, variables significant at $20 \%$ ( $P$ value output of .20 ) between the 2 NIV tolerance groups were introduced into a multivariate logistic regression model with stepwise selection of variables. When a strong relationship was shown between several variables, we used only the variable with the highest correlation. Variables with $>10 \%$ of values missing were not entered into the model, and no replacement method was used (since missing values for one variable do not affect other variables). We used the statistics software's (SAS 9.1, SAS Institute, Cary, North Carolina) procedure logistic stepwise method, which enabled us to combine backward and forward methods, and the Hosmer and Lemeshow goodness of fit test, which showed no evidence of lack of fit.

\section{Results}

\section{Baseline Clinical Characteristics}

We recruited 81 ALS subjects who fulfilled the selection criteria (Figure) and who participated over 34 months. Of the 73 subjects who underwent complete assessment at 1 month, 55 were NIV tolerant, and 18 were poorly tolerant. The poorly tolerant group included 15 subjects who used NIV for 4 hours or less, one subject who refused NIV immediately after the first attempt at using the NIV machine, and 2 subjects who did not attend the 1-month visit because NIV was discontinued after 1 day, due to personal intolerance.

\section{Evaluation at NIV Initiation}

Comparisons of the clinical and demographic baseline characteristics of NIV tolerant versus poorly tolerant subjects who completed the study are displayed in Table 1 . We investigated the effect of smoking (current smoking, smoking history in pack-years). No effect of these variables on NIV tolerance was shown (see Table 1). The respiratory status of tolerant and poorly tolerant subjects on initiation of NIV is presented in Table 2. Four subjects had volume-targeted NIV machines, and 69 had pressure-targeted NIV machines. We describe only the parameters of pressure-targeted NIV machines. Between the tolerant and poorly tolerant groups there were no statistical differences in the pulmonary function values (nocturnal oximetry, slow vital capacity) at time of inclusion, the circumstances at the start of NIV, or the mean elapsed time between NIV indication and NIV initiation (see Table 2). There were, however, statistical differences between the 2 groups at NIV onset, with a lower rate of paradoxical breathing $(P=.03)$ and a lower rate of airway secretion accumulation $(P=.05)$ in the tolerant group than in the poorly tolerant group. Of the 77 subjects who started NIV, 59 (75.6\%) were tolerant on the first day, and 17 (22.4\%) were not. The NIV parameters of 8 of the 69 subjects treated with pressure-targeted NIV were modified in the first month.

\section{Evaluation At 1 Month}

At 1 month, 55/73 subjects (75.3\%) were tolerant of NIV (see Figure), and the tolerant subjects had used NIV for a mean $\pm \mathrm{SD}$ of $8.3 \pm 2.9 \mathrm{~h}$ per $24 \mathrm{~h}$, and $7.8 \pm 1.5 \mathrm{~h}$ per night. In the poorly tolerant group, mean NIV utilization was $4.6 \pm 2.8 \mathrm{~h}$ per 24 hours, and $2.3 \pm 1.4 \mathrm{~h}$ per night. The interface of 2 subjects was changed from a nasal mask to an oronasal commercially available model. No subjects changed from pressure-targeted to volumetargeted NIV, or vice versa.

Among the tolerant subjects, 55/73 had airway secretion accumulation: this includes 50/73 subjects who did not have airway secretions accumulation before NIV start, 2/73 subjects in whom the airway-secretion intervention was successful, and 1/73 subjects who had persistent airway secretion accumulation despite intervention. Among the poorly tolerant subjects, $18 / 73$ had airway secretion accumulation: this includes $12 / 18$ subjects without airway secretion accumulation, $3 / 18$ subjects in whom the airwaysecretion intervention was successful, and 1/18 subjects who had persistent airway secretion accumulation despite intervention.

Importantly, immediate tolerance on the first day predicted NIV tolerance at 1 month: $82.1 \%$ of the initially tolerant subjects remained so at 1 month $(P=.04)$. We found that tolerance to NIV at 1 month was significantly better in subjects with no bulbar involvement (pure spinal form) than in those with bulbar involvement at NIV initi- 
Table 1. Clinical and Demographic Data at Inclusion and at 1 Month

\begin{tabular}{|c|c|c|c|}
\hline & $\begin{array}{l}\text { Tolerant } \\
\text { at } 1 \text { Month } \\
(n=55)\end{array}$ & $\begin{array}{c}\text { Poorly } \\
\text { Tolerant } \\
\text { at } 1 \text { Month } \\
(n=18)\end{array}$ & $P$ \\
\hline Sex & & & .40 \\
\hline Male, no. $(\%)$ & $31 / 55(56.4)$ & $12 / 18(66.7)$ & \\
\hline Female, no. $(\%)$ & $24 / 55(43.6)$ & $6 / 18(33.3)$ & \\
\hline Body mass index, mean $\pm \mathrm{SD} \mathrm{kg} / \mathrm{m}^{2}$ & $23.2 \pm 4.12$ & $23.9 \pm 4.9$ & .50 \\
\hline Active smoking, no. (\%) & $10 / 55(18.2)$ & $5 / 18(27.8)$ & .50 \\
\hline History of smoking, no. (\%) & $13 / 55(23.6)$ & $8 / 18(44.4)$ & .09 \\
\hline Smoking exposure, mean \pm SD pack-years & $6.1 \pm 13.3$ & $13.2 \pm 18.4$ & .08 \\
\hline Place of residence, no. (\%) & & & .30 \\
\hline Home & $55 / 55(100)$ & $17 / 18(94.4)$ & \\
\hline Institution & $0 / 55(0)$ & $1 / 18(5.6)$ & \\
\hline Age at disease onset, mean $\pm \mathrm{SD}$ y & $62.3 \pm 9.0$ & $57.1 \pm 13.1$ & .20 \\
\hline Delay from onset to diagnosis, mean $\pm \mathrm{SD}$ months & $13.9 \pm 12.7$ & $13.8 \pm 18.7$ & .60 \\
\hline Revised El Escorial criteria classification, no. (\%) & & & .60 \\
\hline Probable & $34 / 55(61.8)$ & $10 / 18(55.6)$ & \\
\hline Definite & $21 / 55(38.2)$ & $8 / 18(44.4)$ & \\
\hline $\begin{array}{l}\text { ALS Functional Rating Scale score, mean } \pm \text { SD } \\
\quad(\text { maximum-normal score }=48)\end{array}$ & $29.0 \pm 8.1$ & $26.4 \pm 8.9$ & .20 \\
\hline $\begin{array}{l}\text { Bulbar Norris scale score, mean } \pm \text { SD } \\
\quad(\text { maximum-normal score }=39)\end{array}$ & $30.5 \pm 8.9$ & $22.3 \pm 12.8$ & .01 \\
\hline Gastrostomy, no. (\%) & $3 / 55(5.5)$ & $5 / 18(27.8)$ & .02 \\
\hline $\begin{array}{l}\text { Epworth Sleepiness Scale score, mean } \pm \text { SD } \\
\quad(n=65)(\text { minimum-normal score }=0)\end{array}$ & $8.5 \pm 5.9$ & $7.5 \pm 4.7$ & .80 \\
\hline
\end{tabular}

ation $(P=.02)$. This was further confirmed in the univariate analysis of bulbar impairment subscores on the ALSFRS-R scale and bulbar Norris scale (see Table 2). Multivariate analysis also predicted better tolerance in subjects with no bulbar involvement (Table 3). Further multivariate analysis using ALSFRS-R subscores and Norris bulbar scale total scores was less sensitive and revealed no significant findings (data not shown). When using either the saliva subcomponent of ALSFRS-R (with a total score on 12) and arbitrarily and a priori deciding that the score of $\leq 9 / 12$ corresponds to the bulbar form at NIV initiation, we obtained the following data $(P=.03): 21 / 80$ subjects with the bulbar form at NIV initiation $(26.25 \%)$, of whom $11 / 55(20 \%)$ were tolerant at 1 month, and 9/18 (50\%) were poorly tolerant. This subscore does not change the classification of the subjects' clinical form at NIV initiation as bulbar or non-bulbar (pure spinal) ALS in our study.

When using the ALSFRS-R subscore of 12 to classify the clinical form at initiation, in the multivariate model we still found this an independent prognostic factor $(P=.002)$ : non-Bulbar (pure spinal) form odds ratio 6.0 (95\% CI 1.3-27.2), airway secretion accumulation odds ratio 10.9 (95\% CI 1.6-76.3).

The presence of gastrostomy, related to the bulbar ALS form at NIV initiation, influenced NIV tolerance negatively $(P=.02)$. There was no correlation between age and number of hours of NIV use per day (Spearman $\mathrm{R}=0.14, P=.30)$. Subjects without pooling of secretions had used NIV for a mean of $6.7 \pm 2.7 \mathrm{~h} / \mathrm{d}$ at 1 month, whereas subjects with pooling of secretions had used it for a mean of $5.15 \pm 3.1 \mathrm{~h} / \mathrm{d}(P=.15)$.

Five subjects died before the 1-month evaluation. Four of them presented with progressive hypercapnic coma despite adaptation of NIV settings and/or interface, and one subject presented with acute respiratory distress. Death did not result from NIV discontinuation. Prior to death, all 5 subjects had used NIV for between 3 and 12 hours per day. The 4 subjects who developed progressive hypercapnia while on NIV had used it for 3 to 17 days before death.

The multivariate analysis disclosed 3 predictive factors of good NIV tolerance (see Table 3). The most important and significant predictive factors were absence of airway secretion accumulation prior to starting NIV, and having non-bulbar ALS rather than bulbar ALS at initiation. The association between older age and NIV tolerance was weakly significant.

\section{Discussion}

The aim of the present study was to determine predictors of good NIV tolerance at 1 month, since these may be associated with increased survival and better quality of life. ${ }^{4-6} \mathrm{We}$ will first discuss methodological issues and comparisons with current literature, then the results of 
Table 2. Respiratory Data at Inclusion and at 1 Month

\begin{tabular}{|c|c|c|c|}
\hline & $\begin{array}{l}\text { Tolerant } \\
\text { at } 1 \text { Month } \\
(n=55)\end{array}$ & $\begin{array}{c}\text { Poorly } \\
\text { Tolerant } \\
\text { at } 1 \text { Month } \\
(n=18)\end{array}$ & $P$ \\
\hline Dyssomnia, no. (\%) & $39 / 55(70.9)$ & $11 / 18(61.1)$ & .40 \\
\hline Paradoxical breathing, no. (\%) & $13 / 55(23.6)$ & $9 / 18(50.0)$ & .03 \\
\hline $\mathrm{P}_{\mathrm{aCO}_{2}}>45 \mathrm{~mm} \mathrm{Hg}$, no. $(\%)$ & $24 / 55(43.6)$ & $10 / 18(55.6)$ & .40 \\
\hline Slow vital capacity $<50 \%$ of predicted, no. $(\%)$ & $15 / 54(27.8)$ & $7 / 17(41.2)$ & .30 \\
\hline Nocturnal $\mathrm{S}_{\mathrm{pO}_{2}}<90 \%$ for $>5 \%$ of total measurement time, no. (\%) & $46 / 55(83.6)$ & $14 / 18(77.8)$ & .70 \\
\hline \multirow[t]{2}{*}{ Duration of disease before NIV onset, mean \pm SD months } & $n=55$ & $n=17$ & \\
\hline & $28.6 \pm 22.1$ & $28.1 \pm 24.5$ & .80 \\
\hline Age at NIV initiation, mean \pm SD y & $64.7 \pm 8.7$ & $58.8 \pm 12.3$ & .10 \\
\hline Clinical form at NIV initiation, no. (\%) & & & .02 \\
\hline Pure spinal form (non-bulbar ALS) & $44 / 55(80.0)$ & $9 / 18(50.0)$ & \\
\hline Bulbar involvement & $11 / 55(20.0)$ & $9 / 18(50.0)$ & \\
\hline $\begin{array}{l}\text { ALS Functional Rating Scale sum of subscores of items } 1 \text { and } 3 \\
\text { (maximum score } 8) \text {, no. (\%) }\end{array}$ & & & .05 \\
\hline Severe bulbar impairment: $0-2$ & $5 / 55(9.1)$ & $5 / 18(27.8)$ & \\
\hline Moderate bulbar impairment: $3-7$ & $35 / 55(63.6)$ & $12 / 18(66.7)$ & \\
\hline No bulbar impairment: 8 & $15 / 55(27.3)$ & $1 / 18(5.6)$ & \\
\hline \multirow{2}{*}{$\begin{array}{l}\text { Time elapsed between indication for and initiation of NIV, } \\
\text { mean } \pm \text { SD d }\end{array}$} & $n=54$ & $n=17$ & \\
\hline & $11.6 \pm 15.1$ & $9.6 \pm 15.4$ & .20 \\
\hline \multirow[t]{2}{*}{ Slow vital capacity, mean \pm SD $\%$ of predicted } & $n=45$ & $n=10$ & \\
\hline & $59.9 \pm 21.0$ & $46.8 \pm 18.7$ & .10 \\
\hline Arterial blood gas values before NIV, mean \pm SD & $n=52$ & $n=15$ & \\
\hline $\mathrm{pH}$ & $7.41 \pm 0.03$ & $7.40 \pm 0.05$ & .30 \\
\hline $\mathrm{P}_{\mathrm{CO}_{2}}, \mathrm{~mm} \mathrm{Hg}$ & $47 \pm 9$ & $48 \pm 11$ & .60 \\
\hline $\mathrm{P}_{\mathrm{CO}_{2}}, \mathrm{~mm} \mathrm{Hg}$ & $82 \pm 23$ & $83 \pm 23$ & $>.99$ \\
\hline Circumstances of NIV initiation, no. (\%) & $n=55$ & $n=17$ & .20 \\
\hline Planned & $38 / 55(69.1)$ & $9 / 17(52.9)$ & \\
\hline Urgent/semi-urgent & $17 / 55(30.9)$ & $8 / 17(47.1)$ & \\
\hline NIV tolerance after first day of use & $n=54$ & $n=17$ & \\
\hline Total nocturnal utilization, mean $\pm \mathrm{SD} h$ & $7.4 \pm 2.1$ & $5.1 \pm 3.2$ & .01 \\
\hline NIV pressures, mean $\pm \mathrm{SD} \mathrm{cm} \mathrm{H}_{2} \mathrm{O}$ & $n=52$ & $n=17$ & \\
\hline Inspiratory & $13.6 \pm 4.1$ & $14.7 \pm 3.4$ & .20 \\
\hline Expiratory & $4.6 \pm 1.7$ & $4.8 \pm 1.4$ & .90 \\
\hline Backup breathing frequency, mean \pm SD breaths/min & $15.7 \pm 3.5$ & $14.9 \pm 2.6$ & .60 \\
\hline NIV interface, no. (\%) & $n=52$ & $n=17$ & .30 \\
\hline Commercially & $38 / 52(73.1)$ & $10 / 17(58.8)$ & \\
\hline Individually customized & $14 / 52(26.9)$ & $7 / 17(41.2)$ & \\
\hline Airway secretion accumulation, no. (\%) & $n=53$ & $n=17$ & \\
\hline Before NIV & $3 / 53(5.7)$ & $4 / 17(23.5)$ & .05 \\
\hline
\end{tabular}

the multivariate analysis. The new finding brought by the present study was that the absence of airway secretion accumulation was an independent predictor of good tolerance to NIV in ALS subjects.

\section{Methodological Issues and Comparisons With Literature}

The clinical profiles of our ALS subjects were comparable to those commonly reported in the literature. We retained only definite and probable ALS El Escorial cat- egories in order to strengthen the final diagnosis. NIV was prescribed in our subjects mainly in cases of overt paradoxical breathing and dyssomnia associated with $\mathrm{S}_{\mathrm{pO}_{2}}$ anomalies. ${ }^{22}$ Although slow vital capacity reduction is still the most widely used indicator of restrictive respiratory defect, it is susceptible to variation. ${ }^{23,24}$ Death can occur in patients with slow vital capacity above the critical threshold of $50 \%$ recommended for NIV establishment. ${ }^{25}$ Recent United Kingdom guidelines on NIV indicate that, while clinicians rely on vital capacity, the threshold for initiating 
Table 3. Multivariate Analysis of Predictors of Good Tolerance of Noninvasive Ventilation*

\begin{tabular}{lrr}
\hline \hline & $\begin{array}{r}\text { Odds } \\
\text { Ratio }\end{array}$ & 95\% CI \\
\hline Absence of airway secretions accumulation & 11.5 & $1.3-98.4$ \\
$\begin{array}{l}\text { Pure spinal form (non-bulbar amyotrophic } \\
\text { lateral sclerosis) versus bulbar form }\end{array}$ & 8.5 & $1.6-46.2$ \\
Age at initiation of noninvasive ventilation & 1.1 & $1.03-1.19$ \\
* Global multivariate $P$ of model $=.02$. & & \\
\hline
\end{tabular}

NIV is vital capacity $<50 \%$ of predicted, regardless of symptoms or vital capacity of $50-80 \%$ in the presence of symptoms. ${ }^{26}$ Elevated daytime $\mathrm{P}_{\mathrm{aCO}_{2}}(>45 \mathrm{~mm} \mathrm{Hg})$ is another primary criterion for starting NIV, but reflects a more severe degree of alveolar hypoventilation and therefore exposes the patient to acute respiratory failure and death in the event of exacerbation or intolerance of NIV.7,27

When NIV is initiated following early changes such as those recorded with nocturnal oximetry, and associated with clinical respiratory symptoms, longer survival has been described, compared to patients who started NIV when FVC had declined to $\leq 50 \% .{ }^{28}$ Nevertheless, the converse may be true in patients with bulbar involvement. ${ }^{9}$ Too early NIV introduction can also result in NIV failure and refusal. A multicenter French national randomized study in ALS patients evaluated survival and quality of life with early NIV initiation, comparing 2 groups. One group received early nasal NIV (no clinical signs, only pulmonary function test anomalies). The second group comprised subjects requiring urgent NIV (clinical signs compatible with respiratory insufficiency associated with pulmonary function test anomalies). The study was prematurely stopped for failure and refusal by the early nasal NIV group to continue NIV because of discomfort. ${ }^{29}$

In the present study, NIV tolerance, assessed as NIV use of $>4$ hours per night, was achieved in $75 \%$ of subjects, both immediately in the first session and at 1 month. This finding is consistent with previous studies.7,10,30 In our study, $55 \%$ of the subjects with bulbar involvement at NIV initiation were tolerant. Every effort should, therefore, be made to improve subjects' tolerance. . $7,8,28,30$ One study reported tolerance in $100 \%$ of subjects on discharge following initial hospitalization for NIV initiation. This may be related to a longer duration of hospital stay (on average 12 d). However, in this study, the NIV implementation method differed from our daily practice, and from that of most centers. Pressure support and valves with oronasal masks were administered to all subjects. ${ }^{31}$ In our study, the mean hospital stay for NIV initiation was $2.7 \pm 1.1 \mathrm{~d}$. We believe that thorough information about NIV, describing its advantages and disadvantages, and a positive attitude among the multidisciplinary team involved in both ALS med- ical treatment and NIV initiation in an experienced unit, should reduce NIV refusal and improve tolerance over time, especially in subjects with severe bulbar impairment. When using either the saliva subcomponent of ALSFRS-R (with a total score of 12) and arbitrarily and a priori deciding that the score of $\leq 9 / 12$ corresponds to the bulbar form at NIV initiation, this subscore did not change the classification of the ALS clinical form at NIV initiation as bulbar or non-bulbar (pure spinal) ALS in our study.

Some study limitations have to be acknowledged. We realize that diurnal (10:00 AM to 6:00 $\mathrm{PM}) \mathrm{P}_{\mathrm{aCO}_{2}}$ measurement could have missed some patients with nocturnal hypoventilation who could have benefited from NIV. That is why we associated this parameter with nocturnal oximetry. Polysomnography would have been better for evaluating sleep abnormalities. However, the sleep laboratory could not provide quick appointments, so nocturnal oximetry was the practical option. Polysomnography was not described as mandatory by the ALS consensus conference in France, ${ }^{17}$ for that same reason.

\section{Multivariate Analysis}

Absence of airway secretion accumulation was the best predictor of NIV tolerance in our series. Contrary to our expectations, it was more frequent in non-bulbar ALS at NIV initiation (15\%) than in bulbar ALS (5\%). Airway secretion accumulation probably results from oropharyngeal salivary stasis and respiratory failure. Cough efficiency can be impaired when peak cough flow is $<270 \mathrm{~L} / \mathrm{min}$, which probably favors airway secretion accumulation. Effective cough depends on inspiratory, expiratory, and bulbar muscle function. In some patients expiratory muscle weakness may run parallel with, or even precede, inspiratory muscle weakness. ${ }^{30-32}$ Mustfa et al ${ }^{33}$ reported a positive correlation between inspiratory and expiratory muscle strength and peak cough flow in nonbulbar ALS patients, demonstrating the importance of both muscle groups. Accordingly, mechanically assisted cough improves recruitment of nonventilated lung areas, preventing atelectasis and removing mucus and debris, ${ }^{27,34}$ which should enhance the effect of NIV in improving lung compliance by re-expanding microatelectatic lung areas. ${ }^{11}$ Statistically, all mechanically assisted cough techniques are better than manual techniques for ALS patients, and the CoughAssist is considered the most effective mechanically assisted cough method. ${ }^{33,35}$ Mechanically assisted cough was proposed in our study when peak cough flow was $<270 \mathrm{~L} / \mathrm{min}$, irrespective of the ALS clinical picture.

In some subjects with severe bulbar impairment we observed failure to close the glottis associated or not with a severe dynamic collapse of the upper airways during the exsufflation cycle. ${ }^{36}$ We tried to remove airway secretion accumulation with the Alpha 200 or CoughAssist. The retained technique was based on tolerance and efficacy. If nei- 
ther worked, manual physiotherapy or mechanical insufflation was used. If airway secretion accumulation was not controlled, NIV implementation was nevertheless selected. The limitation of mechanically assisted cough is that it is mostly efficient to clear the upper and middle airways. Intrapulmonary percussive ventilation could be much more efficient to clear the lower airways, but in France it has not been evaluated in patients with ALS. In addition, there is no financial support from the government health system for intrapulmonary percussive ventilation. Mechanically assisted cough applied prior to the use of NIV in the presence of airway secretion accumulation should facilitate NIV adaptation and tolerance in some patients. Systematic verification for the presence of airway secretion accumulation before commencing NIV is, therefore, worthwhile.

The second positive predictor of good NIV compliance was the absence of bulbar involvement at NIV initiation. Many studies have reported greater tolerance in non-bulbar ALS, with a corresponding increased relative risk of death in poorly tolerant subjects. $7,8,10,15$ In those studies, bulbar involvement at NIV initiation was associated with lower adherence and less improvement in quality of life, but NIV was still clinically useful in bulbar ALS.,22 These patients show less tolerance, probably due to problems with handling airway mucus accumulation and saliva. They need intensive and prolonged monitoring at NIV onset ${ }^{20}$ so as to maximize NIV tolerance and adherence. ${ }^{15}$ Gastrostomy is usually performed in patients with more severe bulbar weakness, who have a higher risk of being discomforted by airway secretion accumulation. We expected to observe less tolerance in these patients, as in other studies. ${ }^{4}$ Indeed, the bulbar subjects reportedly have difficulty distinguishing the choking sensation when lying flat from true orthopnea, and perform poorly on volitional tests of respiratory function. They may therefore be considered for NIV when their true respiratory muscle function appears better than that of subjects with good bulbar function. ${ }^{26}$

Based on our own experience and that of other groups, bulbar ALS forms are associated with more mouth leaks with nasal interfaces, more pharyngeal obstruction with oronasal mask, and increased likelihood of further airway secretion accumulation due to ventilator asynchrony. 9,37 We have observed that apnea syndromes were more frequent on polygraph charts in bulbar forms. More systematic performance of polysomnography may be worthwhile to confirm their co-occurrence, even though several studies indicate no clear relationship between bulbar disease and obstructive sleep apnea. ${ }^{38-40}$

The third positive prognosis factor, identified by the multivariate analysis, but which cannot be retained as highly significant, was advanced age (odds ratio 1.1). However, the literature mostly reports young age as being a good prognosis factor. ${ }^{4,8}$ Does acceptance of substitute ventilator techniques differ according to age? Good tolerance in the older group is probably due to optimization of NIV initiation in the hospital and during home visits for all of our subjects. As for the bulbar function at NIV initiation, our findings provide another argument against restricting NIV proposal to certain age brackets.

\section{Conclusions}

Our study enabled us to determine 3 predictive factors of good NIV tolerance, in particular absence of airway secretion accumulation prior to NIV establishment, which should prompt its initiation. The present work provides evidence in support of wide access to units delivering NIV, irrespective of the ALS clinical picture. As patients with bulbar involvement at NIV onset have a poorer prognosis than those without, they can be further disadvantaged by more frequent intolerance to NIV. They need intensive and prolonged monitoring at NIV onset to maximize its compliance. Poor tolerance and intolerance to NIV can perhaps be reduced for some additional ALS patients by controlling airway secretion accumulation by mechanically assisted cough, but this possibility should be confirmed by another study and by solving the problems of the mask model. ${ }^{13}$

Further work is ongoing to assess the factors that can increase tolerance of long-term home mechanical ventilation, and its impact on quality of life.

\section{ACKNOWLEDGMENTS}

We thank the ALS patients who made this study possible; the Association Lyonnaise de Logistique Post Hospitalière for financing the study; and Adeline Roux, Unité de Recherche Clinique, Pôle Information Médicale Evaluation Recherche, Hospices Civils de Lyon, for participating in the statistical analysis.

\section{REFERENCES}

1. Kaplan LM, Hollander D. Respiratory dysfunction in amyotrophic lateral sclerosis. Clin Chest Med 1994;15(4):675-681.

2. Louwerese ES, Visser CE, Bossuyt PM, Weverling GJ. Amyotrophic lateral sclerosis: mortality risk during the course of the disease and prognostic factors. The Netherlands ALS Consortium. J Neurol Sci 1997;152(Suppl):S10-S17.

3. Gil J, Funalot B, Verschueren A, Danel-Brunaud V, Camu W, Vandenberghe N, et al. Causes of death amongst French patients with amyotrophic lateral sclerosis: a prospective study. Eur J Neurol 2008;15(11):1245-1251.

4. Bourke SC, Tomlinson M, Williams TL, Bullock RE, Shaw PJ, Gibson GJ. Effects of non-invasive ventilation on survival and quality of life in patients with amyotrophic lateral sclerosis: a randomised controlled trial. Lancet Neurol 2006;5(2):140-147.

5. Lyall RA, Donaldson N, Fleming T, Wood C, Newsom-Davis I, Polkey MI, et al. A prospective study of quality of life in ALS patients treated with noninvasive ventilation. Neurology 2001;57(1):153-156.

6. Gordon PH, Salachas F, Bruneteau G, Pradat PF, Lacomblez L, Gonzalez-Bermejo J, et al. Improving survival in a large French ALS center cohort. J Neurol 2012;259(12):1788-1792.

7. Aboussouan LS, Khan SU, Banerjee M, Arroliga AC, Mitsumoto H. Objective measures of the efficacy of non-invasive positive-pressure ventilation in amyotrophic lateral sclerosis. Muscle Nerve 2001;24(3): 403-409. 
8. Bourke SC, Bullock RE, Williams TL, Shaw PJ, Gibson GJ. Noninvasive ventilation in ALS. Indications and effect on quality of life. Neurology 2003;61(2):171-177.

9. Farrero E, Prats E, Povedano M, Martinez-Matos JA, Manresa F, Escarrabill J. Survival in amyotrophic lateral sclerosis with home mechanical ventilation: the impact of systematic respiratory assessment and bulbar involvement. Chest 2005;127(6):2132-2138.

10. Gruis KL, Brown DL, Schoennemann A, Zebarah VA, Feldman EL. Predictors of noninvasive ventilation tolerance in patients with amyotrophic lateral sclerosis. Muscle Nerve 2005;32(16):808-811.

11. Kleopa KA, Sherman M, Neal B, Romano GJ, Heiman-Patterson T. BiPAP improves survival and rate of pulmonary function decline in patients with ALS. J Neurol Sci 1999;164(1):82-88.

12. Mustfa N, Walsh E, Bryant V, Lyall RA, Addington-Hall J, Goldstein LH, et al. The effect of noninvasive ventilation on ALS patients and their caregivers. Neurology 2006;66(8):1211-1217.

13. Tintignac A, Gonzalez-Bermejo J. [Follow-up and management of non-invasive home mechanical ventilation]. Rev Pneumol Clin 2009; 65(4):237-247. Article in French.

14. Peysson S, Vandenberghe N, Philit F, Vial C, Petitjean T, Bouhour $\mathrm{F}$, et al, Factors predicting survival following noninvasive ventilation in amyotrophic lateral sclerosis. Eur Neurol 2008;59(3-4):164-171.

15. Lo Coco D, Marchese S, Pesco MC, La Bella V, Piccoli F, Lo Coco A. Noninvasive positive-pressure ventilation in ALS. Predictors of tolerance and survival. Neurology 2006;67(5):761-765.

16. Brooks BR. El Escorial World Federation of Neurology criteria for the diagnosis of amyotrophic lateral sclerosis. Subcommittee on Motor Neuron Diseases/Amyotrophic Lateral Sclerosis of the World Federation of Neurology Research Group on Neuromuscular Diseases and the El Escorial "Clinical limits of amyotrophic lateral sclerosis" workshop contributors. J Neurol Sci 1994;124(Suppl):96-107.

17. [Proceedings of the Consensus Conference on Amyotrophic Lateral Sclerosis. Nice, France; November 2005]. Rev Neurol (Paris) 2006; 162(Spec No 2):4S11-S391. Proceedings in French.

18. EFNS Task Force on Diagnosis and Management of Amyotrophic Lateral Sclerosis. EFNS guidelines on the clinical management of amyotrophic lateral sclerosis (MALS): revised report of an EFNS task force. Eur J Neurol 2012;19(3):360-375.

19. Cedarbaum JM, Stambler N, Malta E, Fuller C, Hilt D, Thurmond B, Nakanishi A. The ALSFRS-R: a revised ALS functional rating scale that incorporates assessments of respiratory function. BDNF ALS Study Group (Phase III). J Neurol Sci 1999;169(1-2):13-21.

20. Volanti P, Cibella F, Sarvà M, De Cicco D, Spanevello A, Mora G, La Bella V. Predictors of non-invasive ventilation tolerance in amyotrophic lateral sclerosis. J Neurol Sci 2011;303(1-2):114-118.

21. Miettinen O. Estimability and estimation in case-referent studies. Am J Epidemiol 1976;103(2):226-235.

22. Consensus Conference. Clinical indications for non-invasive positive pressure ventilation in chronic respiratory failure due to restrictive lung disease, COPD and noctural hypoventilation: a consensus conference report. Chest 1999;116(2):521-534.

23. Gonzalez-Bermejo J. [Indications and equipment needs for ventilatory support in amyotrophic lateral sclerosis]. Rev Neurol (Paris) 2006;162(Spec No 2):4S320-S322. Article in French.
24. Perez T. [Neuromuscular disorders: assessment of the respiratory muscles]. Rev Neurol (Paris) 2006;162(4):437-444. Article in French.

25. Perrin C. [Types of ventilatory support and their indications in amyotrophic lateral sclerosis]. Rev Neurol (Paris) 2006;162(Spec No 2): 4S261-S265. Article in French.

26. National Institute for Health and Clinical Excellence. Motor neuron disease: non-invasive ventilation. London: (CG105) National Institute for Health and Clinical Excellence; 2010. http://publications. nice.org.uk/motor-neurone-disease-cg105. Accessed June 20, 2013.

27. Miller RG, Rosenberg JA, Gelinas DF, Mitsumoto H, Newman D, Sufit R, et al. Practice parameter: the care of the patient with amyotrophic lateral sclerosis (an evidence-based review). Report of the Quality Standard subcommittee of the American Academy of Neurology. Neurology 1999;52(7):1311-1323.

28. Pinto A, de Carvalho M, Evangelista T, Lopes A, Sales-Luís L. Nocturnal pulse oximetry: a new approach to establish the appropriate time for non-invasive ventilation in ALS patients. Amyotroph Lateral Scler Other Motor Neuron Disord 2003;4(1):31-35.

29. Perez T, Salachas F. [Early nasal ventilation in amyotrophic lateral sclerosis: impact on survival and quality of life (the VNP-SLA study)]. Rev Mal Respir 2003;20(4):589-598. Article in French.

30. Bach JR. Amyotrophic lateral sclerosis: predictor for prolongation life by non-invasive respiratory aids. Arch Phys Med Rehabil 1995; 76(9):828-832.

31. Bach JR, Hon A. Amyotrophic lateral sclerosis noninvasive ventilation, uncuffed tracheostomy tubes and mechanically assisted coughing. Am J Phys Med Rehabil 2010;89(5):412-414.

32. Bach JR. Mechanical insufflation/exsufflation: has it come of age? A commentary. Eur Respir 2003;21(3):385-386.

33. Mustfa N, Aiello M, Lyall RA, Nikoletou D, Olivieri D, Leigh PN, et al. Cough augmentation in amyotrophic lateral sclerosis. Neurology 2003;61(9):1285-1287.

34. Winck JC, Gonçalves MR, Lourenço C, Viana P, Almeida J, Bach JR. Effects of mechanical insufflation-exsufflation on respiratory parameters for patients with chronic airway secretion encumbrance. Chest 2004;126(3):774-780.

35. Senent C, Golmard JL, Salachas F, Chiner E, Morelot-Panzini C, Meninger V, et al. A comparison of assisted cough techniques in stable patients with severe respiratory insufficiency due to amyotrophic lateral sclerosis. Amyotroph Lateral Scler 2011;12(1):26-32.

36. Sancho J, Servera E, Diaz J, Marin J. Efficacy of mechanical insufflation-exsufflation in medically stable patients with amyotrophic lateral sclerosis. Chest 2004;125(4):1400-1405.

37. Atkeson AD, Roy Choudhury A, Harrington-Moroney G, Shah B, Mitsumoto H, Basner RC. Patient-ventilator asynchrony with nocturnal noninvasive ventilation in ALS. Neurology 2011;77(6):549-555.

38. Ferguson KA, Strong MJ, Ahmad D, George CF. Sleep-disordered breathing in amyotrophic lateral sclerosis. Chest 1996;110(3):664-669.

39. Kimura K, Tachibana N, Kimura J, Shibasaki H. Sleep-disordered breathing at an early stage of amyotrophic lateral sclerosis. J Neurol Sci 1999;164(1):37-43.

40. Santos C, Braghiroli A, Mazzini L, Pratesi R, Oliveira LV, Mora G. Sleep-related breathing disorders in amyotrophic lateral sclerosis. Monaldi Arch Chest Dis 2003;59(2):160-165.

This article is approved for Continuing Respiratory Care Education credit. For information and to obtain your CRCE

(free to AARC members) visit www.rcjournal.com 